\title{
Unobtrusive Marketing Research Methods: An Overview
}

\author{
Marcus Schmidt ${ }^{1}$ \\ ${ }^{1}$ Institute of Marketing, Copenhagen Business School, Copenhagen, Denmark \\ Correspondence: Marcus Schmidt, Institute of Marketing, Copenhagen Business School, Solbjerg Plads 3, 2000 \\ Frederiksberg, Denmark. Tel: 45-4028-5635. E-mail: ms.marktg@cbs.dk
}

Received: July 25, 2012 Accepted: September 13, 2012 Online Published: October 26, 2012

doi:10.5539/emr.v1n2p172 URL: http://dx.doi.org/10.5539/emr.v1n2p172

\begin{abstract}
Still, most marketing and consumer behavior research is based on self reports from respondents. Subjects are asked to tell researchers about their opinions, intentions and purchase behavior. The advantage of self reports is that they are quick, easy and in most cases fairly reliable. However, research has shown that in some cases results based on self reports may be unreliable and/or invalid. In cases of low involvement and when sensitive topics are involved respondents' answers may be biased due to back- and forwards telescoping, under- and over-reporting etc. In such cases the researcher may look for alternative ways of data collection. In this regard unobtrusive methods appear as a promising and underestimated alternative research technique. The paper shows how unobtrusive methods can be used for analyzing a selection of marketing research problems.
\end{abstract}

Keywords: unobtrusive research methods, audience measurement, consumer behavior, rule based webs

\section{Introduction}

Historically, the survey approach has been the prevailing technique for gathering marketing research information. While observational methods occasionally are employed by marketing researchers their popularity as a vehicle for data collection is clearly ousted by obtrusive methods.

According to Kellehear (1993) "There is today ... a simple and persistent belief that knowledge about people is available simply by asking." There is little doubt, though, that traditional survey methods also have drawbacks. The cardinal conundrum may be summarized such: Can we trust what the respondent tells us she has done, does or intends to do? Is her reporting of past, present and future behavior at all reliable?

In most situations it is believed that responses are trustworthy and describe behavior and opinions correctly or quite accurately. However, depending on the research environment and the phenomenon under investigation, this may not be so. In research settings dealing with low-involvement buying behavior, respondents - due to questionnaire ambiguity - may simply not be able to provide reliable answers to the researcher's questions (Ackoff, Gupta, \& Minas, 1962, 179; Green, Tull, \& Albaum, 1988). Also, respondents' inability to remember correctly how much and/or when behavior occurred may lead to invalid results. Moreover, when sensitive topics are under investigation, findings can turn out useless due to lack of external validity (Sudman \& Bradburn, 1983).

About four decades ago Greyser noticed that there was "an overdependence on interview i.e., obtrusive measures in marketing research" (Greyser, 1973). In a review article on probable marketing research trends in the twenty-first century Malhotra, Peterson, and Kleiser (1999) provide recommendations concerning future methods for collecting marketing research information: "The challenge for. . researchers will be to use. . .technologies. . in natural settings and in less-intrusive ways."

Thanks to recent technological improvements observational or tracking methods are increasing in popularity. This development has been facilitated by advances and breakthroughs in a variety of fields like data warehousing, data mining, and neural networks. Retail scanning, first introduced in the mid-eighties, today has gained widespread use in marketing and consumer research. See Walters (1988, 1991), Walters and MacKenzie (1988), Kumar and Leone (1988), Karande and Kumar (1995), Mayhew and Wiener (1992).

"Classical" examples of empirical unobtrusive studies are (Webb, Campbell, Schwartz, \& Sechrest, 1966):

- The wear of floor tiles in a museum indexed by the replacement rate was used to determine the relative popularity of exhibits 
- The setting of car radio dials brought in for service was used to estimate share of listening audience of various radio stations

- Cigarette buts collected after a football game were treated as indicator of market shares of selected brands In other cases, household garbage and toilet graffiti has been subject to detailed content analysis.

Advantages of unobtrusive methods, according to Kellehear (1993) are:

- The study of actual rather than reported behavior

- Safety (it is regarded discreet and harmless)

- Repeatability (re-checking is possible)

- Non-disruptive, non-reactive

- Research access is easy (cooperation of others is rarely needed)

- Inexpensive

- Good source of longitudinal analysis

While disadvantages are (same source):

- The original records may be of poor quality or distorted

- Records are seen from the point of view of the stranger (decontextualizing)

- Intervening (exogenous) variables may distort data

- Recording is done selective and may be biased

- An over-reliance on a single method

- The application (interrogation) range is limited (the focus is narrow)

The remainder of this paper discusses selected unobtrusive methods for collecting market research data. The methods involve audience measurement, shopping behavior and an analysis of sales dockets.

\section{The Rise of Unobtrusive Methods for Measuring Exposure to Electronic Media}

Since the invention of the people-meter system (introduced in the US in 1987 by Nielsen) considerable progress has been made with regard to the validity of TV-audience measurement. Although people-meter analysts have been struggling with measurement problems like fluctuations in ratings caused by artificial phenomena (Milavsky, 1992), the method has outperformed competing approaches like diaries based on self-reports (Baron 1995). According to many researchers, the methodological virtues of observational techniques like passive-people-meters, scanning-based store audits and comparable electronic measurement devices are caused by their high degree of "unobtrusiveness."

While consumers, whose purchases are registered by a scanner system, do not at all know that their behavior is being measured, members of a people-meter panel are well aware of it. Critical philosophers like Marshall McLuhan describe the people meter as a "hidden microphone" (McLuhan, 1951).

Research indicates that the embedded error involved in unobtrusive measurements is rather modest (Danaher \& Beed, 1993; Danaher, 1995). Unobtrusive methods seems to be free or almost free from several sources of error typically being attributed to data based on self-reports like over/under-reporting, backwards/forwards telescoping, low involvement, ambiguity, non-response, etc.

Thus, it may be to little surprise that research on exposure to electronic media has shifted from reactive methods like self-reported surveys to less-intrusive observational methods. Interestingly, research on exposure to print media is still primarily based on self-reports. However, we believe that exposure to print media can also be scrutinized by way of unobtrusive measurement techniques. This paper reports on two surveys using unobtrusive methods for collecting data on consumer's advertising and shopping behavior.

\section{Fingerprints as a Proxy for Readership of Sales Flyers: An Empirical Assessment}

The first published effort to assess the audience of a print medium by analyzing fingerprints can be traced back to 1934. It became known as the "200,000 Fingerprints Study" and was conducted by Time Magazine (DuBois 1963). The purpose of the study was to investigate new ways for measuring readership of Time Magazine. A sample of magazines was distributed amongst subscribers. All issues consisted of paper that had been exposed to careful chemical manipulation prior to being distributed (a solution of silver-nitrate crystals) (Note 1). The type of paper used was found to be very sensitive to fingerprints, and about 500 issues were collected some days later. 
More than $90 \%$ of the issues contained fingerprints. According to DuBois (1963), the cost of the study was $\$ 1.25$ per fingerprint or $\$ 270,000$ for the study. This amount corresponds to somewhere between $\$ 15,000,000$ and $\$ 20,000,000$ today! Unfortunately, the only available source regarding the 1934 study is DuBois' (1963) two-page summary. It is therefore difficult to assess the specifics of the research setup. From a pure measurement perspective the reported findings appear to be impressive, indeed. However, some technical comments seem appropriate. Firstly, why should a subscriber pay for receiving a magazine and then not even read it? Secondly, as far as we can assess, the study has no managerial implications and lacks generalizeability. In a 1976 study Greene and Maloney considered the problem of finding an alternative method to measure print media audiences, noting that, "Magazine audience research has been going on for forty years without any proof that what readers claim they read is what they actually did read" (Greene \& Maloney, 1976). The objective of their study then was to find out whether the analysis of fingerprints appearing on magazines could be used as a proxy for readership of the appropriate magazine. Greene and Maloney conducted two small pilot studies. The first test consisted of three persons who were asked to leaf through about 100 pages of magazine paper. In a second test a small sample of magazines was collected from at doctor's office. For analytical purposes the authors used Silver-Nitrate and Ninhydrin, a chemical that was a rather recent chemical development within forensic research at the time of their study.

From a methodological perspective, the pilot studies by Greene and Maloney were characterized as a disappointment. One possible explanation may be that they used Silver Nitrate (now outdated) for detecting fingerprints. They also employed Ninhydrin, but in the 1970s even forensic experts were somewhat unfamiliar with using this liquid. Today, researchers have about forty years of experience with the chemical.

However, the major reason for the disappointing outcome of the 1976 study was caused by a simple miscomprehension of how the fingerprints-approach can and cannot be used for measuring readership. The study attempted to identify individual fingerprints, i.e. linking fingerprints to a specific person, and this turned out to be impossible in their experiment (Fingerprints were identified on around $5 \%$ of the considered pages). But the presence of a positively identifiable fingerprint is not a necessity for proving that a given page has been touched by an individual and thus probably has been read by that person. One could argue though, that the appearance of a fingerprint on a page only proves that the page has been touched, while it does not prove that the page has been read.

In a new study the authors conducted an empirical analysis based on 4604 flyer-pages across 117 issues (Schmidt, Krause, \& Solgaard, 2012). Table 1 shows the results of our analysis. Notice that there is a correspondence between the number of pages of a flyer and estimated readership. It appears that the fingerprint approach works for "voluminous" flyers like catalogues ("Idényt") but not necessarily for flyers with less than thirty pages or so. Results were rather encouraging, indicating that the method in certain situations may serve as an estimate of readership. Advertising management may use the fingerprint-approach as an alternative method for assessing readership measures obtained by the traditional survey method, provided that the flyers' number of pages exceeds an unspecified threshold number of pages (maybe 80-100 pages or so). However, more research on the issue is needed.

Table 1. Fingerprint analysis of a sample of flyers

\begin{tabular}{|c|c|c|c|c|c|c|c|c|c|c|c|c|}
\hline & I & II & III & IV & $\mathrm{V}$ & VI & VII & VIII & IX & $\mathrm{X}$ & XI & XII \\
\hline $\begin{array}{l}\text { Producer/ } \\
\text { Distributor }\end{array}$ & $\begin{array}{l}\text { No. } \\
\text { of } \\
\text { Issues }\end{array}$ & $\begin{array}{l}+ \\
\text { FP }\end{array}$ & $\begin{array}{l}- \\
\text { FP }\end{array}$ & $\begin{array}{l}\text { Valid } \\
\text { pages } \\
\text { of } \\
\text { Issue }\end{array}$ & $\begin{array}{l}\text { Tot. } \\
\text { no. } \\
\text { pages } \\
\text { I* IV }\end{array}$ & $\begin{array}{l}\text { Pages } \\
\text { with } \\
\text { FP } \\
\text { II*IV }\end{array}$ & $\begin{array}{l}\text { Total } \\
\text { no. } \\
\text { valid } \\
\text { FP }\end{array}$ & $\begin{array}{l}\text { Ratio } \\
\text { with } \\
\text { FP } \\
\text { VII*V }\end{array}$ & $\begin{array}{l}\text { Ratio } \\
\text { FP } \\
\text { issues } \\
\text { VII*VI }\end{array}$ & $\begin{array}{c}\text { "Readership" } \\
\text { II/I }\end{array}$ & $\begin{array}{l}\text { FPs } \\
\text { right-hand } \\
\text { pages }\end{array}$ & $\begin{array}{l}\text { FPs } \\
\text { left-hand } \\
\text { pages }\end{array}$ \\
\hline Idényt & 25 & 19 & 6 & 118 & 2950 & 2242 & 324 & 0.11 & 0.15 & $76 \%$ & 219 & 105 \\
\hline Brugs & 16 & 5 & 11 & 22 & 352 & 110 & 34 & 0.09 & 0.31 & $31 \%$ & 25 & 9 \\
\hline Real & 13 & 4 & 9 & 22 & 286 & 88 & 11 & 0.04 & 0.13 & $30 \%$ & 9 & 2 \\
\hline Netto & 44 & 5 & 39 & 14 & 616 & 70 & 12 & 0.02 & 0.17 & $11 \%$ & 6 & 6 \\
\hline ElKøb & 9 & 3 & 6 & 6 & 54 & 18 & 6 & 0.08 & 0.33 & $33 \%$ & 6 & 0 \\
\hline Isport & 6 & 1 & 5 & 4 & 24 & 4 & 1 & 0.03 & 0.25 & $17 \%$ & 1 & 0 \\
\hline Kol.S. & 4 & 1 & 3 & 22 & 88 & 22 & 7 & 0.07 & 0.32 & $25 \%$ & 6 & 1 \\
\hline Totals & 117 & 38 & 79 & - & 4370 & 2554 & 395 & 0.09 & 0.16 & - & 272 & 123 \\
\hline
\end{tabular}




\section{An Assessment of Consumers' Shopping Lists}

Another study conducted by Schmidt (2012) involved the analysis of 871 shopping lists collected inside and outside supermarkets and discount stores. The 871 shopping lists contained a total of 8047 identifiable items or an average of 9.2 items per list.

About one third of shopping lists (297 out of 871) contained at least one positively identified brand (i.e. Ajax, Coca Cola, Nescafe, Whiskas, Kellogg's, Adidas etc.). In total 447 items could be identified as brands. In other words: Only 5.6\% of items (447/8047) appearing on shopping lists turned out to be known brands.

Table 2 shows the most popular brands according the Danish consumers' shopping lists. The most popular brand turns out to be "Kærgaarden" a spreadable butter. It is a hybrid product, partly butter and partly margarine. It appears that producers of the shopping lists want to be sure that the purchaser (not necessarily the person who produced the list) wants to be sure that the brand purchased is "Kærgaarden" and not a different butter or margarine brand. Notice that international brands like Ajax, Sanex and Knorr only rarely appear on shopping lists. For instance, Ajax only appeared on nine of 871 lists (1\% of all lists).

Table 2. Most Popular Brands Appearing on 871 Shopping Lists

\begin{tabular}{rlrll}
\hline \multicolumn{1}{c}{ No. } & \multicolumn{1}{c}{ Brand } & Frequency & \multicolumn{1}{c}{ Product category } & \multicolumn{1}{c}{ Producer } \\
\hline 1 & Kærgaarden & 33 & Spreadable butter & Arla \\
2 & A38 & 18 & Fermented milk & Arla \\
$3-4$ & Ajax & 9 & Detergent & Colgate \\
$3-4$ & Merrild & 9 & Coffee (national brand) & Sara Lee \\
$5-7$ & Cheasy & 7 & Cheese & Arla \\
$5-7$ & Lätta & 7 & Margarine & Unilever \\
$5-7$ & Sanex & 7 & Shampoo & Sara Lee \\
$8-10$ & Cultura & 6 & Yoghurt & Arla \\
$8-10$ & Gajo & 6 & Yoghurt & Arla \\
$8-10$ & Knorr & 6 & Sauce & Unilever \\
\hline
\end{tabular}

Table 3 shows the number of brands within selected product categories. For instance 56 shopping lists listed chocolate. Of these every forth list contained the name of a specific brand (Kinder, Mars etc.) Within chocolate, coffee and shampoo the ratio of brands to generic product names was at least one to five. With regard to bread only $1 \%$ of lists mentioned a specific brand name. Notice also the total lack of correspondence between the number of brands within a category and the ad spending within the same category.

Table 3. Percentage of Brands within Selected Product Categories

\begin{tabular}{lccrr}
\hline $\begin{array}{l}\text { Product } \\
\text { category }\end{array}$ & $\begin{array}{c}\text { Percent of items } \\
\text { within category that } \\
\text { are brands }\end{array}$ & $\begin{array}{c}\text { Percentage of shopping } \\
\text { lists where product } \\
\text { category appears }\end{array}$ & \multicolumn{2}{c}{$\begin{array}{c}\text { Total spending on advertising } \\
\text { in Denmark in USD (2000, } \\
\text { Gallup) }\end{array}$} \\
\hline Chocolate & 25 & 6 & 56 & $9,231,231$ \\
Coffee & 22 & 9 & 79 & $3,101,745$ \\
Shampoo & 21 & 6 & 56 & $3,803,881$ \\
Cigarettes & 19 & 2 & 16 & $3,985,036$ \\
Butter/margarine & 16 & 33 & 287 & $2,313,282$ \\
Chips & 15 & 3 & 27 & $2,944,596$ \\
Soft drink & 11 & 10 & 85 & $9,107,438$ \\
Toothpaste & 10 & 5 & 40 & $3,338,516$ \\
Cheese & 7 & 25 & 217 & n.a. \\
Sausages & 7 & 5 & 43 & 355,697 \\
Beer & 6 & 4 & 36 & $12,775,904$ \\
Bread & 1 & 33 & 283 & $7,606,542$ \\
\hline Source & 15 & & &
\end{tabular}

Source: TNS Gallup Denmark. Media covered: TV, radio, newspapers, weeklies, magazines, flyers, outdoor advertising and movies. 


\section{Combined Purchases: Analysis by Way of A Rule Based Web}

Sometimes, marketing researchers are interested in the combined purchases by consumers. With regard to advertising and distribution management it might be of interest for management to look at the combination of purchases. An example: Are bananas purchased in combination with apples or rather in combination with carrots? Figure 1 shows a rule based web of about 30,000 purchases across 1000 consumers.

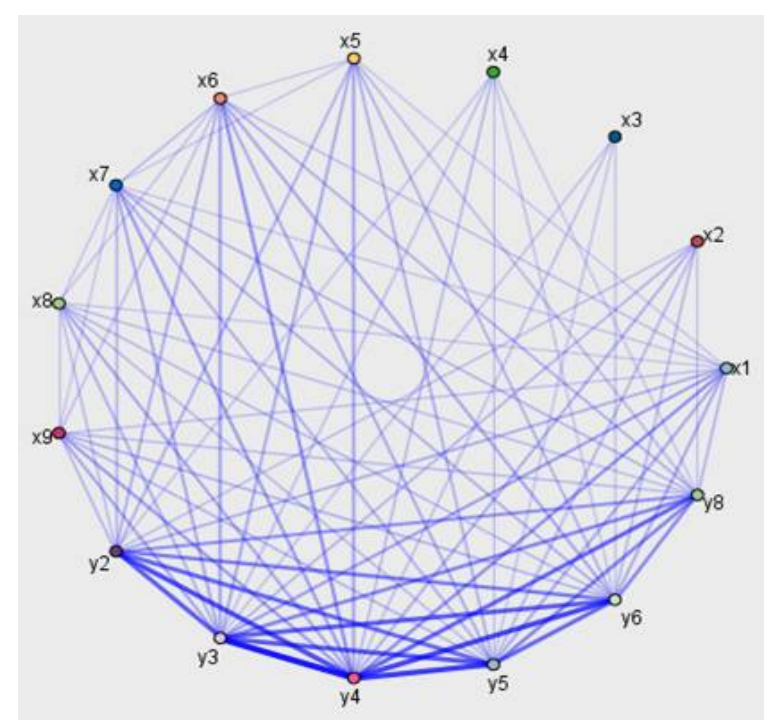

Figure 1. Combined purchases of selected meat and fruit products

Notice: $\mathrm{x} 1=$ Pate, $\mathrm{x} 2=$ Pork, $\mathrm{x} 3=$ Delicacies, $\mathrm{x} 4=$ Salami snacks, $\mathrm{x} 5=$ Smoked pork, $\mathrm{x} 6=$ Bacon, $\mathrm{x} 7=$ Ham, $\mathrm{x} 8=$ Saveloy, $\mathrm{x} 9=$ Sausages, $\mathrm{y} 2=$ Carrots, $\mathrm{y} 3=$ Apples, $\mathrm{y} 4=$ Bananas, $\mathrm{y} 5=$ Avocados, $\mathrm{y} 6=$ Green peppers, $\mathrm{y} 8$ $=$ Pink apples. $\mathrm{y} 1$ and $\mathrm{y} 7$ refer to products with links to other products that fell below the threshold level and thus were excluded from the web.

Technically there is an association between the "fatness" of a link and the tendency of combined purchases. For instance, $12 \%$ of consumers who purchased bacon (x6) also purchased smoked pork (x5) during the same shopping trip. However as much as $51 \%$ of consumers who purchased apples (y3) also purchased bananas (y4) during the same shopping trip. Notice also that since only $8 \%$ of consumers purchased both smoked pork (x5) and salami snacks (x5) there is no link between the two products in the web.

\section{Discussion}

The present paper showed three applications of unobtrusive methods, (1.) the fingerprint approach for audience measurement, (2.) shopping lists and (3.) a rule based web of combined purchases. We think that nonreactive marketing research methods will gain popularity in the coming decades. Unobtrusive methods will most probably not render traditional survey methods superfluous. The rise of social networks has resulted in a boost of online surveys. Almost every of this researchers' students, be it undergraduate or graduate, today use Facebook, Twitter, Linkedin or email lists for conducting surveys. They are fast and effective vehicles for data gathering. The major problem is the representativeness of online surveys. So far, young people (students) are overrepresented in such surveys. However, we believe that this bias will decline across time. Even today a growing number of parents and grandparents use social media for being updated about their children and grandchildren.

Unfortunately, nonreactive methods also constitute a potential threat to the anonymity of respondents. Placing cookies, Trojan horses or spy applications on a PC or smartphone makes it possible for a company to get a wealth of information from the respondent or customer. It is well-known that companies like Amazon, Facebook, Google etc. use or intend to use these facilities. It will be a challenge to the companies and especially to commercial users of market research data to develop a set of guidelines protecting the consumer from unobtrusive data collection. In general, the consumer ought to know exactly which information about him/her a company is collecting and utilizing. While it may be a professional priority of a market research company to respect the respondents' anonymity a commercial seller may not be interested in respecting this anonymity. 


\section{References}

Ackoff, R. L., Gupta, S., \& Minas, J. S. (1962). Scientific method: Optimizing applied research decisions. New York: John Wiley.

Baron, R. (1995). The passive people meter: An agency perspective. Journal of Advertising Research, 35(2), 71-71.

Bradburn, N. M., \& Sudman S. (1988). Polls and surveys. San Francisco: Jossey-Bass.

Danaher, P. J., \& Beed, T. W. (1993). A Coincidental survey of people meter panelists: Comparing what people say with what they do. Journal of Advertising Research, 33(1), 86-92.

Danaher, P. J. (1995). What happens to television ratings during commercial breaks?. Journal of Advertising Research, 35(1), 37-47.

DuBois, C. N. (1963). Time Magazine's fingerprint's study. Proceedings: $9^{\text {th }}$ Conference, Advertising Research Foundation (pp. 7-8). New York: Advertising Research Foundation.

Green, P. E., Tull D. S., \& Albaum, G. (1988). Research for marketing decisions. Englewood Cliffs, NJ: Prentice Hall.

Greene, J. D., \& Maloney, J. F. (1976). Fingerprints can’t test for validity. Journal of Advertising Research, 16(3), 49-50.

Greyser, S. A. (1973). In M. L. Ray, Unobtrusive marketing research methods. Columbus, OH: Franklin University Library, foreword.

Karande, K. W., \& Kumar, V. (1995). The effect of brand characteristics and retailer policies on response to retail price promotions: Implications for retailers. Journal of Retailing, 71(3), 249-278.

Kellehear, A. (1993). The unobtrusive researcher - A guide to methods. St. Leonards, Australia: Allen and Unwin.

Kumar. V., \& Leone, P. R. (1988). Measuring the Effect of Retail Store Promotions on Brand and Store Substitution. Journal of Marketing Research, 25(5), 178-185.

Malhotra, N. K, Peterson, M., \& Kleiser, S. B. (1999). Marketing research: A state-of-the-art review and directions for the twenty-first century. Journal of the Academy of Marketing Science, 27(2), 160-183.

Mayhew, G. E., \& Winer, R. S. (1992). An empirical analysis of internal and external reference prices using scanner data. Journal of Consumer Research, 19, 62-70.

McLuhan, M. (1951). The mechanical bride. New York: Vanguard Press.

Milavsky, J. R. (1992). How good is the A. C. Nielsen people-meter system?. Public Opinion Quarterly, 56, 102-115.

Schmidt, M. (2012). Retail shopping lists: Reassessment and new insights. Journal of Retailing and Consumer Services, 19, 36-44. http://dx.doi.org/10.1016/j.jretconser.2011.08.006.

Schmidt, M., Krause N., \& Solgaard, H. (2012). Using a forensic research method for establishing an alternative method for audience measurement in print advertising. Journal of Multidisciplinary Research, 4(1), 5-20.

Walters, R. G. (1988). Retail promotions and retail store performance: A test of some key hypotheses. Journal of Retailing, 64(2), 153-180.

Walters, R. G., \& MacKenzie, S. M. (1988). A structural equations analysis of the impact of price promotions on store performance. Journal of Marketing Research, 25, 51-63.

Walters, R. G. (1991). Assessing the impact of retail price promotions on product substitution, complementary purchase, and interstore sales displacement. Journal of Marketing, 55(April), 17-28.

Webb, E. J., Cambell, D. T., Schwartz R. D., \& Sechrest, L. (1966). Unobtrusive measures - nonreactive research in the social sciences. Chicago: Rand McNally.

\section{Note}

Note 1. The procedure of exposing respondents to a hazardous solution without informing them beforehand probably would be regarded illegal today, due to laws protecting citizens from environmental and work related risks. Moreover, in many Western countries laws often severely limit the use of toxic material. 